\title{
Origin and Composition of Seasonal Labrador Sea Freshwater
}

\author{
SUNKE SCHMIDT \\ Leibniz-Institut für Meereswissenschaften IFM-GEOMAR, Kiel, Germany \\ UWE SEND \\ Scripps Institution of Oceanography, University of California, San Diego, La Jolla, California
}

(Manuscript received 17 December 2004, in final form 11 September 2006)

\begin{abstract}
The depth of winter convection in the central Labrador Sea is strongly influenced by the prevailing stratification in late summer. For this late summer stratification salinity is as important as temperature, and in the upper water layers salinity even dominates. To analyze the source of the spring and summer freshening in the central region, seasonal freshwater cycles have been constructed for the interior Labrador Sea, the West Greenland Current, and the Labrador Current. It is shown that none of the local freshwater sources is responsible for the spring-summer freshening in the interior, which appears to occur in two separate events in April to May and July to September. Comparing the timing and volume estimates of the seasonal freshwater cycles of the boundary currents with the central Labrador Sea helps in understanding the origin of the interior freshwater signals. The first smaller pulse cannot be attributed clearly to either of the boundary currents. The second one is about three times stronger and supplies $60 \%$ of the seasonal summer freshwater. Transport estimates and calculated mixing properties provide evidence that its source is the West Greenland Current. The finding implies a connection also on interannual time scales between Labrador Sea surface salinity and freshwater sources in the West Greenland Current and farther upstream in the East Greenland Current. The freshwater input from the West Greenland Current thus also is the likely pathway for the known modulation of Labrador Sea Water mass formation by freshwater export from the Arctic (via the East Greenland Current), which implies some predictability on longer time scales.
\end{abstract}

\section{Introduction}

The Labrador Sea plays an important role in the North Atlantic thermohaline circulation and is a region with pronounced thermal and haline variability on interannual time scales (Lab Sea Group 1998). Temperature, as well as salinity, also has a strong seasonal cycle. Different sources and mechanisms have been suggested for the origin of these interannual and seasonal variabilities. They vary from local sources and sinks, Hudson Bay outflow, Baffin Bay waters, and Canadian Archipelago freshwater exports to East Greenland ice melt and East Greenland Arctic freshwater export. Various authors describe a connection between freshwater export from the Arctic via the East Greenland

\footnotetext{
Corresponding author address: Sunke Schmidt, Leibniz-Institut für Meereswissenschaften IFM-GEOMAR, Düsternbrooker Weg 20, 24105 Kiel, Germany.

E-mail: sschmidt@ifm-geomar.de
}

Current and the convection activity in the Labrador Sea (Aagaard and Carmack 1989; Dickson et al. 1996; Pickart et al. 2002; Haak et al. 2003; Kwok et al. 2004), for which the Great Salinity Anomaly of the 1970s is a pronounced example (Dickson et al. 1988), but the exact pathway and mechanism has only been speculation to date.

The interannual stratification variability in the Labrador Sea has its origin to some extent in year-to-year differences of convection activity and depth (Marshall and Schott 1999). These changing convection depths result from varying atmospheric forcing and variable stratification buildup in the previous summer. The atmospheric forcing is correlated with the North Atlantic Oscillation (NAO) index (Marshall et al. 2001). High $\mathrm{NAO}$ has the effect of stronger heat loss in the central Labrador Sea (LS) relative to low NAO because of prevailing stronger cold and dry continental winds from Canada. However, no strong year-to-year correlation between convection and NAO can be found (e.g., Lilly

DOI: $10.1175 / \mathrm{JPO} 3065.1$ 

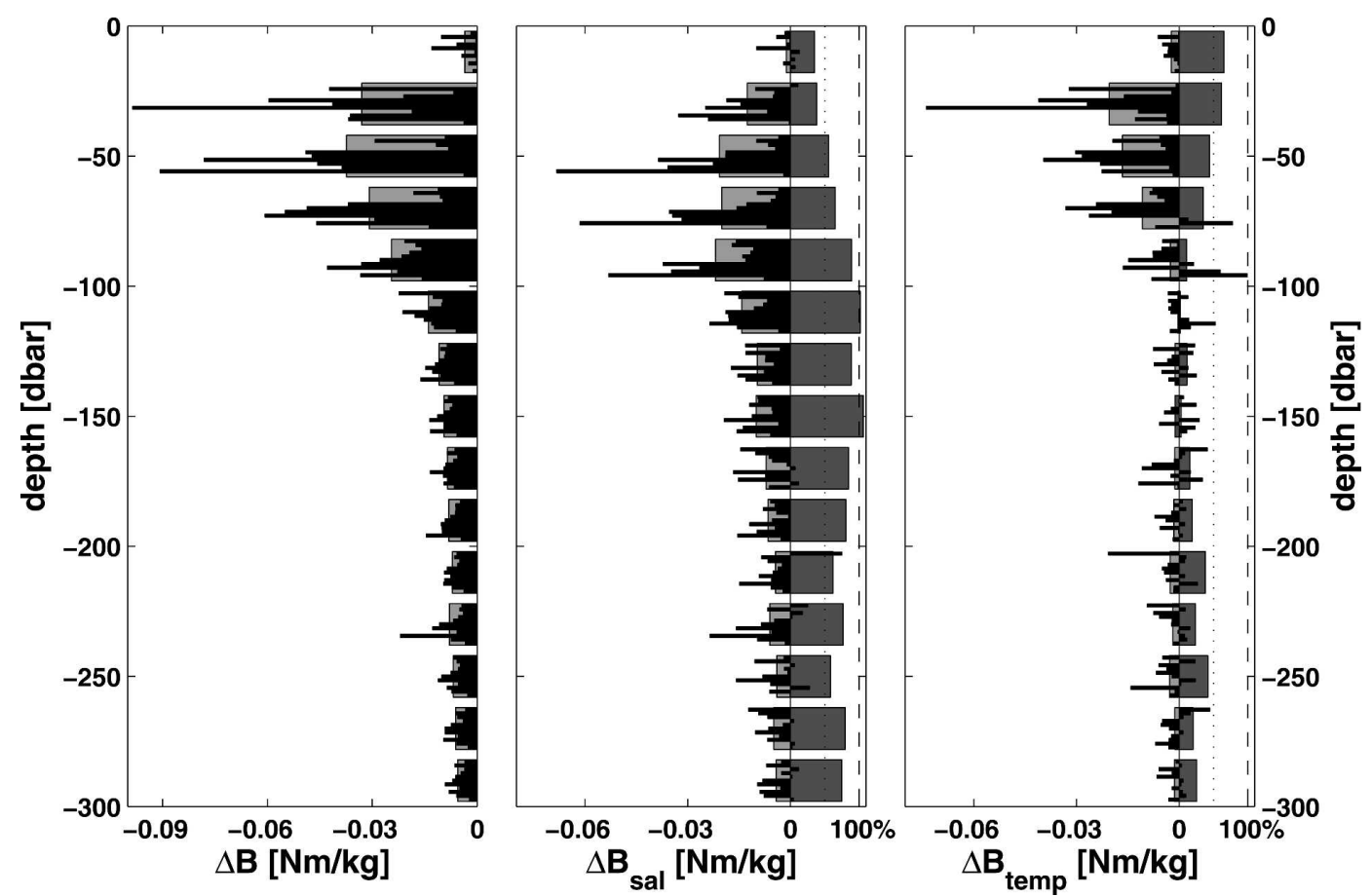

FIG. 1. Change in buoyancy content in 20-dbar steps for LS summer stratification. Shown (from left to right) are the mean integrated buoyancy content differences, the haline and thermal part of it (light gray bars), the yearly values (small black bars), and the percentage of total mean (dark gray bars). Note that the values of $\Delta B(z)$ shown give the amount of buoyancy that needs to be removed from the surface to the depth $z$ in order to mix $20 \mathrm{dbar}$ deeper.

et al. 2003). One likely reason is the large importance of stratification for this region (The Lab Sea Group 1998).

A revealing analysis of the stratification can be performed by calculating the buoyancy content separately for temperature and salinity. The buoyancy content, $B$, is defined as the depth integral of buoyancy (e.g., Marshall and Schott 1999):

$$
B\left(z_{1}\right)=-g \int_{z_{1}}^{0} \rho_{z_{1}}-\rho(z) d z
$$

where $g$ is the gravity, $z_{1}$ and $\rho_{z 1}$ are the depth and density at the bottom of the layer considered, and $\rho(z)$ is the density profile. With the approximation that $\alpha_{\theta}$, the thermal expansion coefficient, and $\beta_{S}$, the haline expansion coefficient, are comparable in magnitude for $\rho_{0}$, a constant reference density, and $\rho(z), \rho$ can be linearized as

$$
\rho(z)=\rho_{0}\left\{1-\alpha_{\theta}\left[\theta(z)-\theta_{0}\right]+\beta_{S}\left[S(z)-S_{0}\right]\right\},
$$

where $\theta$ is the potential temperature, $S$ is salinity, and $\theta_{0}$ and $S_{0}$ are their constant reference values. Thus the buoyancy content can be written as

$B\left(z_{1}\right)=-g \int_{z_{1}}^{0} \alpha_{\theta}\left[\theta_{z_{1}}-\theta(z)\right]-\beta_{S}\left[S_{z_{1}}-S(z)\right] d z$.
This equation of the buoyancy content can be split into a temperature and salinity term, $B\left(z_{1}\right)=B_{\theta}\left(z_{1}\right)+$ $B_{S}\left(z_{1}\right)$ :

$$
\begin{aligned}
& B_{\theta}\left(z_{1}\right)=-g \int_{z_{1}}^{0} \alpha_{\theta}\left[\theta_{z_{1}}-\theta(z)\right] d z \quad \text { and } \\
& B_{S}\left(z_{1}\right)=g \int_{z_{1}}^{0} \beta_{S}\left[S_{z_{1}}-S(z)\right] d z .
\end{aligned}
$$

For a better vertical resolution of the buoyancy stratification we define

$$
\Delta B(z)=B(z+10 \mathrm{~m})-B(z-10 \mathrm{~m}) .
$$

The value $\Delta B(z)$ indicates how much buoyancy has to be removed throughout the water column between $0 \mathrm{~m}$ and $\mathrm{z}$ to overcome the density increase between $z-10$ $\mathrm{m}$ and $z+10 \mathrm{~m}$, that is, to further deepen the mixed layer $20 \mathrm{~m}$. In Fig. $1 \Delta B, \Delta B_{S}$, and $\Delta B_{\theta}$ are presented for summer CTD profiles from the years 1992 to 2002. It shows the dominant role of the salinity versus temperature stratification in the depth range from $60 \mathrm{~m}$ down to more than $300 \mathrm{~m}$. Temperature stratification is dominant in the top $40 \mathrm{~m}$ and in greater depth (not shown). These results are the motivation to concentrate on the 


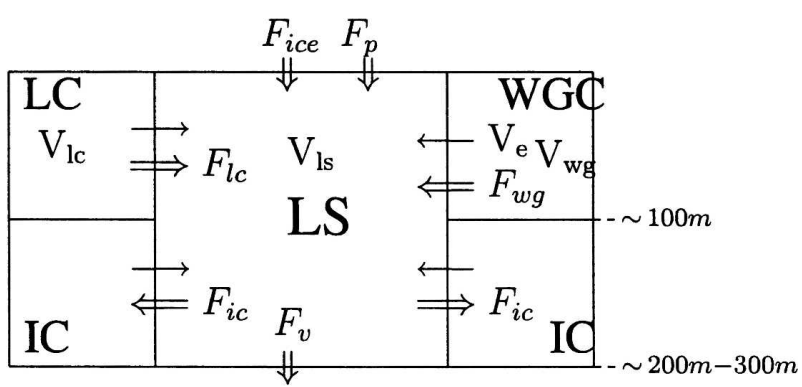

FIG. 2. Schematic overview for freshwater and volume fluxes. Single arrows indicate volume and double arrows show the corresponding freshwater fluxes. The freshwater fluxes $(F)$ are shown for sea ice meltwater (ice), precipitation minus evaporation $(p)$, West Greenland Current (wg), Irminger Current (ic), and Labrador Current (lc); $V$ : the volumes.

analysis of the origin and composition of the freshwater input leading to this stratification. The focus of this work is the freshening part of the seasonal salinity cycle.

Figure 2 illustrates a schematic section through the LS and its boundary currents. Single arrows show the direction of volume fluxes and double arrows indicate corresponding freshwater fluxes. Here $V_{i}$ are volumes of water masses and $F_{i}$ is related freshwater fluxes, with $F_{\text {ice }}$ net local sea ice melt, $F_{p}$ precipitation minus evaporation, $F_{v}$ vertical mixing freshwater flux, and the subscripts to $F$ in the figure are ic: the Irminger Current, wg: the West Greenland Current, lc: the Labrador Current, and ls: the Labrador Sea. The freshwater volumes relative to the local seasonal salinity maximum will be denoted with $v_{I}$, and $V_{e}$ is the volume carried into the LS in a time interval, here from the West Greenland Current (WGC), also written as $V_{e}=\chi V_{\text {wg }}$ with $\chi$ the percentage of waters lost from the WGC and $V_{\text {wg }}$ the volume circulating in the WGC in the corresponding time interval. The paper as a whole examines the possible sources $F_{\text {ice }}, F_{p}, F_{v}, F_{\text {lc }}$, and $F_{\text {wg }}$ for the summer freshening, that is, for the change $\Delta v_{\mathrm{ls}}$ during April to September. Here $v_{\mathrm{ls}}$ changes by the fluxes according to

$$
\frac{\Delta v_{\mathrm{ls}}}{\Delta t}=F_{\mathrm{ice}}+F_{p}+F_{v}+F_{\mathrm{lc}}+F_{\mathrm{wg}} .
$$

All fluxes together are assumed to balance in the annual mean, but individual fluxes may become important at different times.

The loss of boundary current water to the interior Labrador Sea is documented by drifter observations (see below). It is not clear whether this is an exchange process with zero net mass flux or whether there is net detrainment-like mass flux out of the boundary current, but this does not impact subsequent calculations or con-

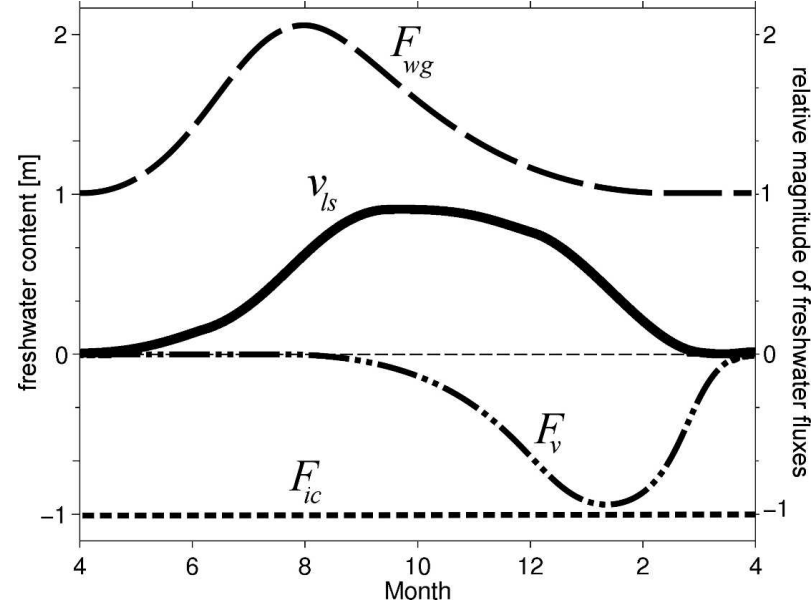

FIG. 3. Qualitative sketch for the temporal evolution of the central LS freshwater content and the freshwater fluxes. Here $F_{\text {wg }}$ is the freshwater flux from the WGC, $F_{\text {ic }}$ the IC freshwater flux assumed constant here, $F_{v}$ the central Labrador Sea vertical freshwater flux at $150 \mathrm{~m}$, and $v_{\mathrm{ls}}$ the central LS top 150-m freshwater volume expressed as freshwater column. Assuming that the background $F_{\mathrm{wg}}$ is balanced by constant $F_{\mathrm{ic}}$, the anomalous $F_{\mathrm{wg}}$ input is balanced by the convective $F_{v}$. The potential effect from the LC is omitted for simplicity, but the argument would be equivalent to that for the WGC here.

clusions. Probably this horizontal transfer of water takes place because of small-scale eddy mixing along the path of the West Greenland Current and Irminger Current.

The scenario that we envisage for the freshwater balances in the central Labrador Sea is sketched schematically in Fig. 3. We assume that the input of water from the WGC $\left(F_{\mathrm{wg}}\right)$ is taking place all the time and provides some background freshwater supply (as in the winter months), which is balanced by a constant flux $F_{\text {ic }}$ of saltier Irminger Current waters also supplied from the boundary currents at slightly deeper levels. This is justified by the fact that in winter no other compensating process is known to exist. Because of this balance only changes in the freshwater availability in the West Greenland Current have an impact on the central Labrador Sea. Vertical mixing is known to be a major freshwater pathway out of the upper layers of the central Labrador Sea; thus $\mathrm{F}_{v}$ has a maximum in January/ February and stops at the end of the mixed layer deepening/convection phase (March/April). Since we assume that $F_{\text {ic }}$ and $F_{\text {lc }}\left(F_{\text {lc }}\right.$ not shown in sketch for simplicity) do not have strong seasonal changes, an increase in $F_{\mathrm{wg}}$ would be reflected as an increase in $v_{\mathrm{ls}}$. Seasonal changes in $F_{\text {ic }}$ are neglected since there is no evidence for large variability, while for $F_{\mathrm{lc}}$ we will show below that a potential contribution is small relative to $F_{\mathrm{wg}}$. 
A probable separate mechanism for boundary current exchange is large eddies in the boundary current west of Cape Desolation. Model studies by Eden and Böning (2002) or Katsman et al. (2004) and observations (Lilly et al. 2003) indicate an enhanced eddy kinetic energy (EKE) maximum west of Cape Desolation at the end of the convective season (Eden and Böning 2002). The background activity of this process can be included in the steady part of $F_{\mathrm{wg}}$ above. Whether the seasonal maximum in this EKE can generate a freshwater pulse in the interior Labrador Sea is addressed in the discussion section.

In the following we will quantitatively argue that the overall freshening in the Labrador Sea $\Delta v_{\mathrm{ls}}$ from April to September can be understood as two separate freshwater events. This separation allows a better determination of the origin of the central LS freshening. We will show that they are related to pulselike increases in the freshwater available for entrainment from the West Greenland Current, as shown in the sketch, and a smaller equivalent one, possibly in the Labrador Current. The subsequent winter decrease of Labrador Sea freshwater occurs mainly by mixing the near-surface freshwater progressively deeper until March/April $\left(F_{v}\right.$ in the sketch).

Analyzing the sources of the central Labrador Sea summer freshening helps in understanding the pathways of freshwater/salinity anomalies, like the Great Salinity Anomaly in 1970s (Dickson et al. 1988). Conversely, knowledge of freshwater changes in the sources (e.g., East Greenland ice melt or Fram Strait freshwater export) would allow some predictability of the late summer central Labrador Sea stratification and thus of the subsequent convection activity.

\section{Data}

Our analysis contains data from the Bedford Institute of Oceanography (BIO) hydrographic online database and mooring data ( $T$ and $S$ ) from central LS moorings between 1996 and 2001. The data were used to construct mean seasonal cycles, similar to the one by Khatiwala et al. (2002). The temporal and spatial distribution of the used data is explained in detail by Houghton and Visbeck (2002). Their Fig. 3 shows the spatial distribution of the data. As Houghton and Visbeck (2002) show, the Cape Farewell region (middle right panel in their Fig. 4) is much less sampled than the region of Fyllas Bank (upper middle and upper right panel), which impacts our analysis (see below). We excluded from the analysis all data sampled during the GSA of the 1970s (Dickson et al. 1988; Lazier 1995). Using data from that period would lead to anomalous low winter

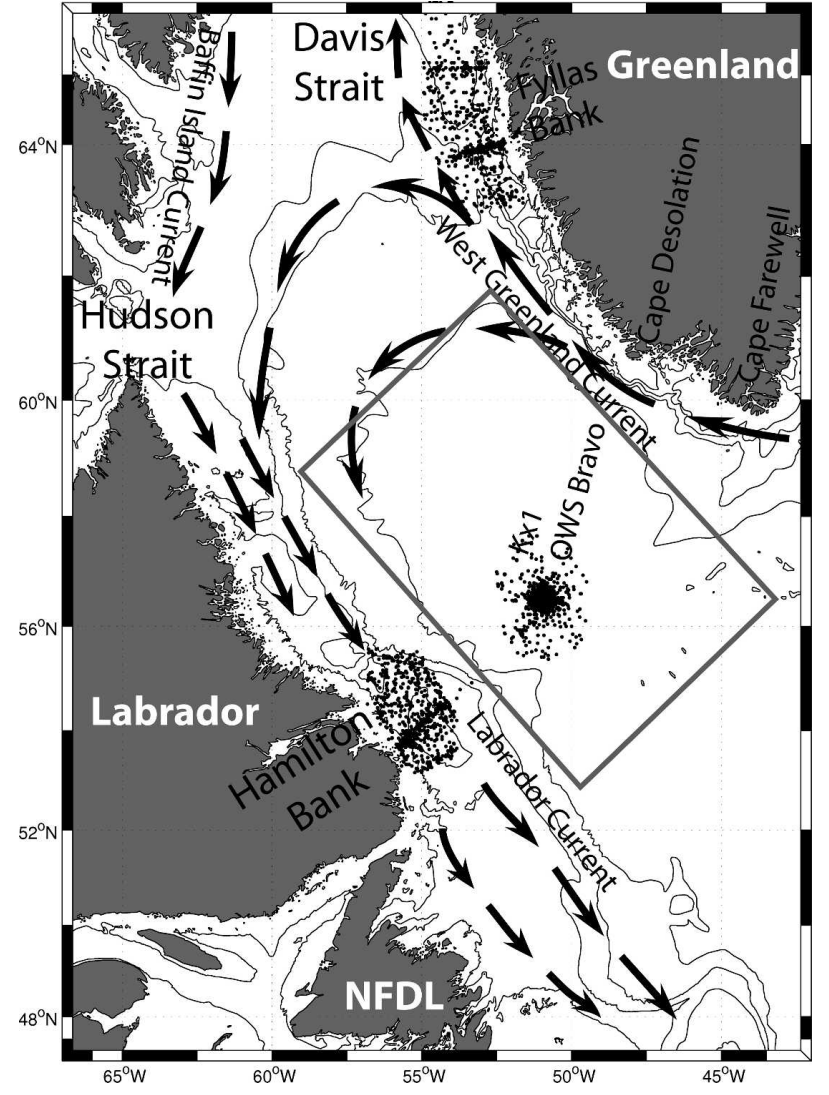

FIG. 4. Labrador Sea map with schematic currents, areas of interest, and places mentioned. Black dots indicate positions of used data; 200-, 1000-, 2000-, and 3000-m isobaths are shown.

salinities and therefore to a lower amplitude in the seasonal cycle relative to normal years. A deformation of the seasonal cycle by using data from the GSA in the LS is also mentioned by Khatiwala et al. (2002).

For the boundary currents, data were used from the areas that are best sampled throughout the year: these are Fyllas Bank for the WGC and Hamilton Bank for the LC (Fig. 4). There are no other equally suitable areas in the boundary currents that have been sampled as regularly in every month of the year over a long period.

\section{Local freshwater signal}

A mean seasonal salinity cycle from data within a radius of $150 \mathrm{~km}$ of Ocean Weather Ship (OWS) Bravo (Fig. 4) is constructed. This radius is chosen because it covers the interior region of the convection activity, which is the regime that we seek to understand, and at the same time it excludes the boundary current regime and is a well-sampled area. Taking data from a larger 

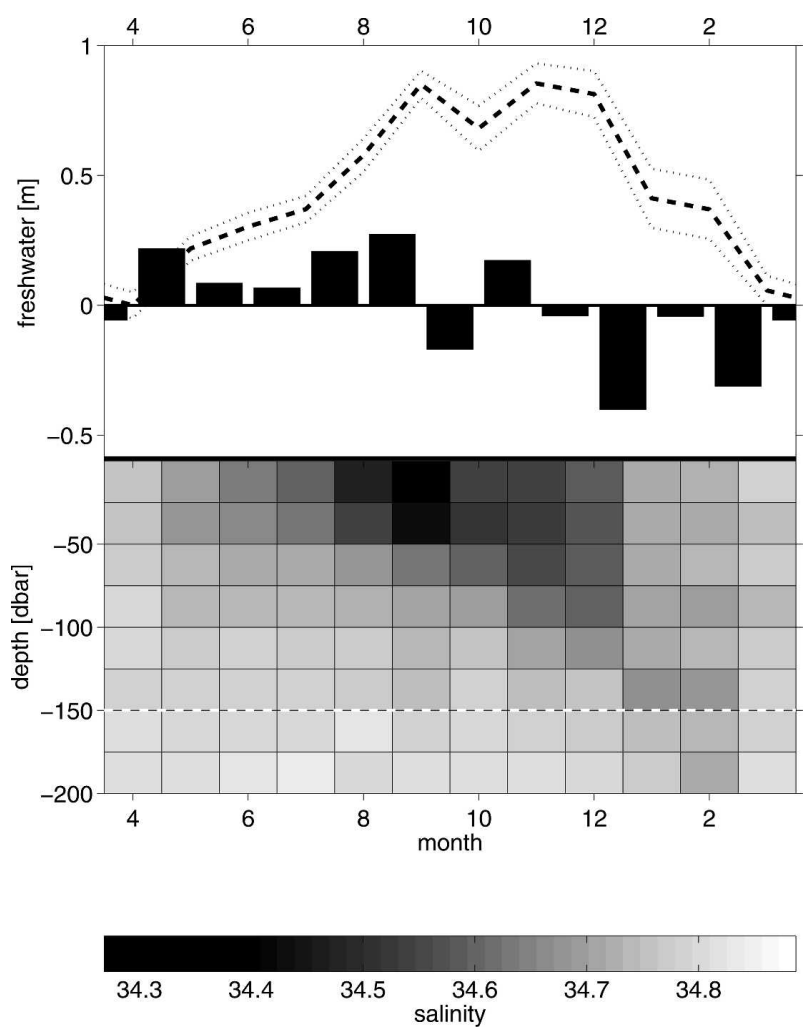

FIG. 5. (bottom) Central Labrador Sea mean salinity and (top) top 150-m freshwater column anomaly cycle; the top panel shows the evolution in freshwater content (dashed curve) and its rms error (dotted curve) throughout the year starting with the saltiest monthly mean (34.768 psu) and the corresponding freshwater change in between months (bars). Ticks are centered on the first of each month.

area (like the complete Labrador Sea) would decrease signals by spreading them out over time and thus make the timing of a pulse generated by lateral processes harder to determine. The mean salinity profile in $25-$ dbar steps for each month can be seen in the lower part of Fig. 5. A mean freshwater content cycle for the top $150 \mathrm{~m}$ was calculated from these data, starting and taking as reference the month with highest salinity, here April (upper part Fig. 5). The bars indicate the necessary monthly freshwater flux, expressed as the amount of freshwater that has to be supplied to or taken from the surface layer by local sources, advection/stirring, and convection. The rms error of the freshwater amount (dotted curve) for May has to be treated with caution; because of very few sample years it is unrealistically low. This does not completely question the robustness of the first peak because the data for April and June are robust. Only the timing of this first pulse could be one month later or spread across two months; if on average May would have higher salinities, the freshwater pulse or part of it would be post- poned to June. Spread over two months this pulse would lose some of it significance, as it is no longer as dominant relative to local sources.

\section{a. Freshening period}

The data show $80 \mathrm{~cm}$ of freshwater input from April to September. This value is about $20 \%$ larger than that by Lazier (1980) and Khatiwala et al. (2002). Both used only the top $100 \mathrm{~m}$ and their data included the GSA. Using only the top $100 \mathrm{~m}$ in our calculations would lead to $70 \mathrm{~cm}$ of freshwater input [i.e., $5 \%$ more than Lazier (1980) and Khatiwala et al. (2002)]. In the central LS we use $150 \mathrm{~m}$ instead because the freshwater layer exceeds $100 \mathrm{~m}$ in some years. The larger freshwater input found in our analysis can be explained by having removed the effect of the GSA, as described above. Inspecting the monthly freshwater change, these $80 \mathrm{~cm}$ of freshwater occur in two separate freshwater signals: a smaller one between April and May $(20 \mathrm{~cm})$ and a larger input between July and September $(50 \mathrm{~cm})$, a further 10-cm freshwater spread over the whole freshening period. In view of the standard deviations and the few data in May, the smaller pulse may not be significant, while the July-September freshening is a highly robust result.

To translate these freshwater column values into the volume of freshwater, the calculated seasonal cycle is regarded representative for a $550 \mathrm{~km} \times 750 \mathrm{~km}$ area $\left(\sim 0.41 \times 10^{6} \mathrm{~km}^{2}\right.$ : see Fig. 4$)$. This area was chosen by analyzing late summer salinity sections through the LS (not shown). It is larger than the one used by Khatiwala et al. (2002) and smaller than the one used by Lazier (1980) or Houghton and Visbeck (2002). With this area a freshwater input of $v_{\mathrm{ls}}=3.28 \times 10^{11} \mathrm{~m}^{3}$ (corresponding to the $80-\mathrm{cm}$ column $)$, or $24 \mathrm{mSv}\left(\mathrm{Sv} \equiv 10^{6} \mathrm{~m}^{3} \mathrm{~s}^{-1}\right)$, results between April and September. The two separate freshwater signals are then $\Delta v_{\mathrm{ls} \text { (Apr-May) }}=0.8 \times 10^{11} \mathrm{~m}^{3}$ $(20 \mathrm{~cm})$ and $\Delta v_{\mathrm{ls}(\mathrm{Jul}-\mathrm{Sep})} \approx 2 \times 10^{11} \mathrm{~m}^{3}(50 \mathrm{~cm})$. The overall freshwater input of $24 \mathrm{mSv}$ is between the 11 mSv obtained by Khatiwala et al. (2002) and the $30 \mathrm{mSv}$ by Lazier (1980). The September and October saltening and following freshening can to a large degree be explained by the rms error. At the end of the summer the freshwater in the central LS consists of $20 \%$ freshwater from the first input signal and $60 \%$ from the second input signal. This previously nondescribed separation into two freshwater fluxes gives an improved ability to track back their origin.

\section{b. Deep mixing period}

In addition to the two freshening phases, Fig. 5 shows two large and distinct salt inputs into the upper layers 
of the central Labrador Sea (negative bars): one from December to January and another one from February to April. Since these are related to the vertical mixing fluxes $F_{v}$, it is at first surprising that there are two separate events with no freshwater flux in between. The reason for this appearance is the lower 150-m boundary for our calculations. In January the mixed layer depth exceeds the 150-m depth, resulting in a freshwater export across this boundary by vertical mixing. As cooling and deepening of the mixed layer continues, the salinity values initially do not change much in the upper $150 \mathrm{~m}$, resulting in a freshwater flux close to zero from January to February. This changes when deep convection (or so-called violent mixing) sets in and causes mixing with deeper saltier waters in March, resulting in the second negative freshwater pulse from February to March. If we perform our calculations with a deeper boundary, the first event is found from January to February, thus merging the previously two separate peaks into one. We do not intend to analyze the process of convection in the central Labrador Sea here in more detail. In the following we focus on the freshening period.

\section{Local freshwater sources}

Before looking at remote laterally transferred freshwater sources for the central Labrador Sea it is appropriate to analyze the local sources in more detail. Local sources are precipitation minus evaporation $\left(F_{p}\right)$ and locally melting sea ice $\left(F_{\text {ice }}\right)$. Restratification after convection might also contribute to the freshwater signal by advecting or mixing local water masses surrounding the convection site.

\section{a. Precipitation and evaporation}

The total yearly precipitation minus evaporation is about $40 \mathrm{~cm}$ and for the time period of interest here (April until September) it is $F_{p}=15 \mathrm{~cm}$ in the northwest North Atlantic (Walsh and Portis 1999). Similar freshwater input can be found in Sathiyamoorthy and Moore (2002) $\left(F_{p} \approx 17 \mathrm{~cm}\right)$ and in precipitation climatologies $(15-20 \mathrm{~cm})$. Since spread in time, the precipitation is unlikely to be the source for any of the two freshwater signals found, but it can account approximately for the $10 \mathrm{~cm}$ of freshwater that were found to be spread over the time, roughly $20 \%$ of the observed freshening from April to September.

\section{b. Local sea ice melt}

Although the timing of the maximum ice extent and melt onset in the larger LS region fit well with the first freshwater signal, it is known that the central LS stays free of sea ice (Mysak et al. 1990; Wang et al. 1994; and others). Hardly any sea ice drifts into the central LS; most of it melts in the boundary current area. The 100and 3000-m isobaths represent approximately the minimum and maximum ice extent between February and May (Peterson et al. 2000). Central LS tracer analyses in early summer by Khatiwala et al. (1999) do not show significant influence of local sea ice melt. All this indicates that it is very unlikely that local sea ice melt contributes to the first freshwater signal. The second freshwater pulse also cannot be influenced by local sea ice melt because there is no sea ice present in the LS area in late summer. Thus we assume $F_{\text {ice }}=0$ throughout the seasonal freshening period.

\section{c. Restratification/capping}

Because the data used for constructing Fig. 5 cover only a small part of the Labrador Sea, we have to investigate whether horizontal advection or mixing within the interior Labrador Sea can contribute to the observed seasonal freshening. During the restratification phase, which follows the deep convective homogenization, the surrounding waters (which are largely outside our area analyzed) cap the local water at the convection site (Marshall and Schott 1999). This could represent a local freshwater input if the directly adjacent regions have a lower salinity than the area in which deep convection/violent mixing took place. However, Pickart et al. (2002) show that the waters surrounding the convection site within the interior LS had higher salinities directly after convection (and not lower as might be expected). To check whether this was a typical situation, profiling float data from recent years were analyzed. They show a similar behavior.

This somewhat surprising result will not be discussed in further detail here but needs investigation. The relevant conclusion for this study is that the capping of the convection site during the restratification process cannot contribute to the freshening signals observed. If any, one would expect a negative contribution to the freshwater signal.

\section{Boundary currents}

As no local process can explain the observed freshening and the vertical fluxes have the wrong sign, the boundary currents are the only possible origin of the freshening signals found in the central LS. Loder et al. (1998), Houghton and Visbeck (2002), and Khatiwala et al. (2002) note that the WGC as a freshwater source for the Labrador Sea region cannot be neglected, but they argue that it is much less important than water 
originating north of Davis Strait. All those authors include the Labrador shelf in the freshwater budget of the whole Labrador Sea. In that case, the shelf region with the Labrador Current dominates the freshwater volume changes of the Labrador Sea. However, for the central Labrador Sea, and thus the regions of convection activity, the balances are different, and Schmidt (2003) and Myers (2005) already pointed out that in this case the dominance of Davis Strait sources does not necessarily need to be true.

\section{a. West Greenland Current}

The WGC is the continuation of the East Greenland Current (EGC) and has the same water mass characteristics. We now analyze the top $100 \mathrm{~m}$, instead of 150 $\mathrm{m}$ like in the central LS, to avoid contamination from the upper parts of the underlying Irminger Sea water (ISW). The WGC is described in detail by Buch (2000), Cuny et al. (2002), Schmidt (2003), and others. The WGC flows along the shelf break with mean speeds between 30 and $35 \mathrm{~cm} \mathrm{~s}^{-1}$. These speeds are calculated from drifter data by Cuny et al. (2002). The described drifters need $21 \pm 7.5$ days from Cape Farewell to Fyllas Bank (their Godthåb section: see Fig. 4). An average width of $120 \mathrm{~km}$ for the WGC is assumed here for volume calculations. The seasonality of freshwater within the WGC has not been described in detail so far; even the mean annual freshwater carried by the current varies from author to author. Because of lack of data the current is assumed to be constant in volume transport along the Greenland coast from Cape Farewell to Fyllas Bank. The freshwater content change throughout the year is now calculated similar to the one in the central LS. The seasonal salinity and freshwater anomalies are shown in Fig. 6.

Because the standard year-round hydrographic sections at Cape Farewell do not include the upper shelf and core of the West Greenland Current (because of large amounts of small icebergs and packs of multiyear ice), we cannot use hydrographic data from Cape Farewell. The first open, ice free area with year-round, multiyear data is Fyllas Bank, where the freshwater cycle in Fig. 6 has been calculated. To estimate the freshwater error we have studied a large amount of sources on Greenland terrestrial icemelt and runoff. Hardly any of them give clear estimates of volumes. Observations and models do not agree and the spread of model results is enormous (Paterson 1994; Wadhams 2000). According to observations by Reeh (1985) and Mineral Resource Administration for Greenland (1998), there is no major freshwater source between Cape Farewell and Fyllas Bank, that is, $1.7 \mathrm{mSv}$ freshwater and $3.6 \mathrm{mSv}$ icebergs between Cape Farewell and Disko Bay (Reeh 1985),

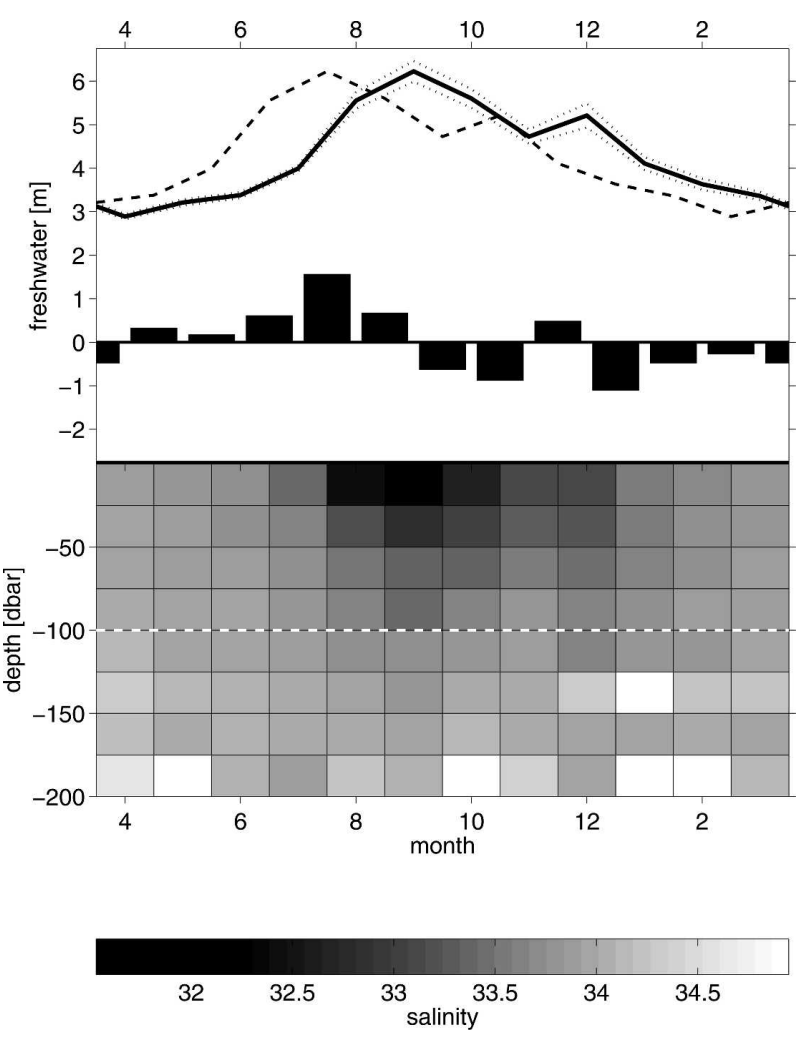

FIG. 6. (bottom) West Greenland Current mean salinity and (top) top 100-m freshwater column anomaly cycle with reference salinity 34.768 psu at Fyllas Bank (solid curve) and its rms error (dotted curve). Estimated timing for Cape Farewell (dashed curve); bars indicate the intermonthly change in freshwater; ticks are centered on the first of each month.

which is farther north and twice the distance to Fyllas Bank. Even in the unlikely case that all freshwater would enter and all icebergs would melt in the WGC before Fyllas Bank, $5.3 \mathrm{mSv}$ freshwater is negligible relative to about $80 \mathrm{mSv}$ WGC freshwater pulse (see next paragraph below) for our estimates. Thus even though Fyllas Bank is past the main bifurcation of the WGC, water mass properties have not changed greatly. However, there may be a slight underestimate in the calculated freshwater amount of the WGC because of somewhat higher salinities at Fyllas Bank relative to Cape Farewell. The reason must be mixing along the way of the WGC with central Labrador Sea or Irminger Sea waters. Based on the above speeds of the WGC the freshwater event analyzed here at Fyllas Bank is assumed to originate from Cape Farewell slightly less than a month earlier (dashed curve).

The freshwater anomaly cycle in the WGC (Fig. 6) has one freshwater pulse, not two like the central LS. This one maximum has its peak at Fyllas Bank between July and September, so we infer this peak to have 
passed Cape Farewell between June and August, about one month prior to the second central LS signal. Using the mean current and width of the WGC to obtain a volume for it, this additional freshwater volume is in the order of $80 \mathrm{mSv}$ or $v_{\mathrm{wg}} \approx 6.2 \times 10^{11} \mathrm{~m}^{3}$ for the upper $100 \mathrm{~m}$ from June to August. An indication about how much WGC water enters into the central LS is given by Cuny et al. (2002), 6 of 19 drifters. We take this as a rough estimate for about $\chi \approx 30 \%$ of WGC waters that is transferred into the central LS. As mentioned earlier, it is not clear whether this is a mixing process with zero net transport or a volume transport of WGC waters into the Labrador Sea. The difference in the subsequent freshwater calculations using either mixing or transport into the central Labrador Sea is very small.

For the freshwater flux we will assume that it results from input of the percentage $\chi$ of the water circulating in the WGC. Taking $T_{\mathrm{wg}}$ to be the transport of the WGC and $V_{\mathrm{wg}}=T_{\mathrm{wg}} \Delta t$ as the volume circulating in a time interval $\Delta t, \chi T_{\mathrm{wg}}$ is the input rate and $\chi T_{\mathrm{wg}} \Delta t=$ $V_{e}=\chi V_{\mathrm{wg}}$ the volume transferred into the interior.

The freshwater flux $F_{\text {wg }}$ can be calculated from the salinity change in the Labrador Sea induced by the volume of WGC waters incorporated into the LS:

$$
\Delta S_{\mathrm{ls}}=\frac{S_{\mathrm{ls}} V_{\mathrm{ls}}+S_{e} V_{e}}{V_{\mathrm{ls}}+V_{e}}-S_{\mathrm{ls}} \approx\left(S_{\mathrm{wg}}-S_{\mathrm{ls}}\right) \frac{V_{e}}{V_{\mathrm{ls}}},
$$

where $S_{\mathrm{ls}}, S_{\mathrm{wg}}$ are LS and WGC salinities and $V_{e} \ll V_{\mathrm{ls}}$. This is equivalent to adding the freshwater volume

$$
\Delta v_{\mathrm{ls}}=-\frac{\left(S_{\mathrm{wg}}-S_{\mathrm{ls}}\right)}{S_{\mathrm{ls}}} V_{e} .
$$

Thus

$$
F_{\mathrm{wg}} \approx-\frac{V_{e}}{\Delta t} \frac{\left(S_{\mathrm{wg}}-S_{\mathrm{ls}}\right)}{S_{\mathrm{ls}}} .
$$

We assume that the minimum flux of $F_{\mathrm{wg}}$ during the smallest salinity contrast $\left(S_{\mathrm{ls}}-S_{\mathrm{wg}}\right.$ in April) is balanced by $F_{\text {ic }}$ (as in the schematic in Fig. 3), so only an increase in the WGC would yield a freshwater change in the Labrador Sea of

$$
\Delta v_{\mathrm{ls}, i}=-\frac{S_{\mathrm{wg}, i}-S_{\mathrm{wg}, 0}}{S_{\mathrm{ls}}} V_{e}=\chi v_{\mathrm{wg}, i},
$$

where $v_{\mathrm{wg}, i}$ is the monthly freshwater anomaly relative to April. Adding this over the 3 months, June until August, gives the aforementioned $6.2 \times 10^{11} \mathrm{~m}^{3}$ for $v_{\mathrm{wg}}$; thus $\Delta v_{\mathrm{ls}}=2 \times 10^{11} \mathrm{~m}^{3}$. This is surprisingly close to the estimated volume required to generate the summer freshwater anomaly in the Labrador Sea.

Since both the timing and volume of the estimated WGC freshwater fluxes fit well with the observed sec-
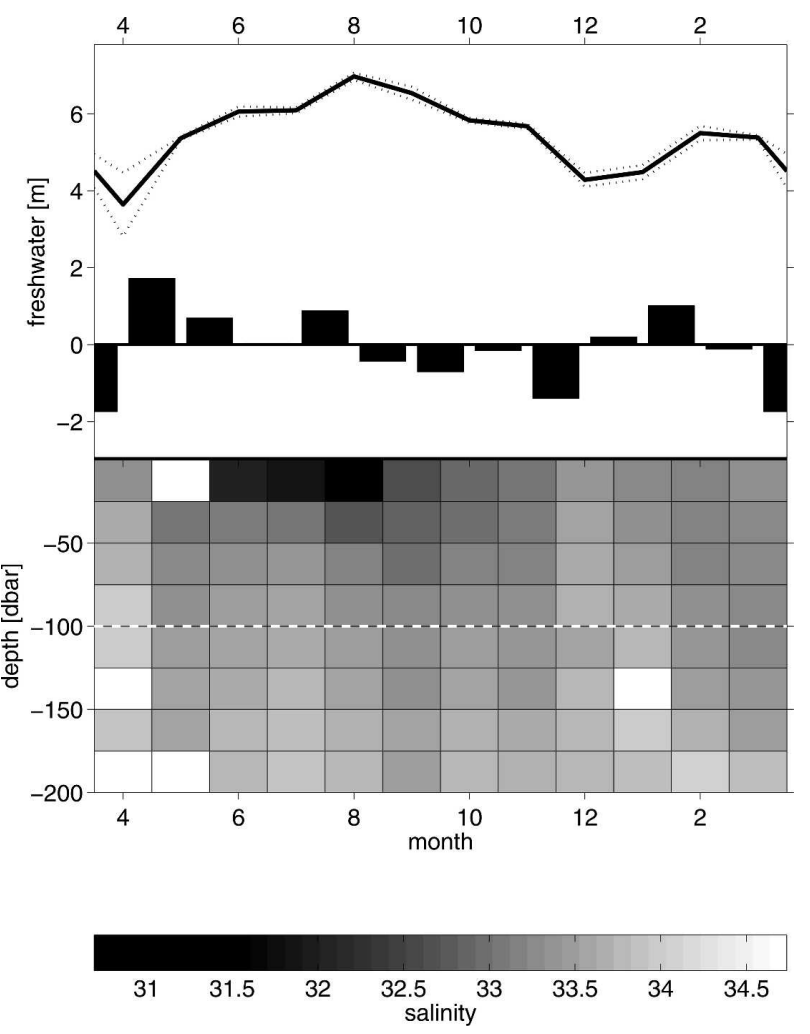

FIG. 7. (bottom) Labrador Current mean salinity and (top) top 100-m freshwater column anomaly cycle with reference salinity 34.768 psu at Hamilton Bank (dashed curve) and its rms error (dotted curve). Bars indicate the intermonthly change in freshwater; ticks are centered on the first of each month.

ond freshwater signal in the LS, we conclude that the WGC is its likely source.

\section{b. Labrador Current}

The Labrador Current (LC) is described in detail by, for example, Lazier and Wright (1993), Mertz et al. (1993), and Loder et al. (1998). The core is centered over the shelf break. The current is fed by the Hudson Strait Current (HSC) (e.g., Drinkwater 1988; Myers et al. 1990), Baffin Island Current (BIC), and two WGC branches. Water from these sources lines up in the cross-shelf direction in the LC: close to shore water from the Hudson Bay area is dominant, followed by BIC waters, while farther offshore waters of both WGC branches are dominant (Schmidt 2003).

A similar seasonal freshwater time series, like in the central LS and in the WGC, is calculated for the top 100 $\mathrm{m}$ of the LC (Fig. 7). The analysis is limited to the top $100 \mathrm{~m}$, as for the WGC, because of the underlying Labrador Sea Water (LSW) and ISW. The LC shows a different behavior from the WGC. Two freshwater signals can be distinguished: a large one in April/May and 
a small one in July/August. The timing of both is similar to the signals in the central LS, but the intensity is inverted. To derive freshwater volumes, for estimation purposes the following values are used (Cuny et al. 2002): $25 \mathrm{~cm} \mathrm{~s}^{-1}$ current speed (appropriate for April to August; otherwise, the flow is rather variable) and 250$\mathrm{km}$ width (core only $50 \mathrm{~km}$ wide but a large shelf area). This leads to a freshwater anomaly circulating $O(120$ $\mathrm{mSv}$ ) from April to May and a further increase of 50 $\mathrm{mSv}$ in August.

Using Eq. (11) and the associated assumptions to estimate the volume that needs to be transferred from the LC into the central Labrador Sea in order to generate the freshwater signals there results in

$$
\chi=\frac{\Delta v_{\mathrm{ls}}}{v_{\mathrm{lc}}},
$$

where the above $120 \mathrm{mSv}$ correspond to a LC freshwater volume of $v_{\mathrm{lc}} \approx 8 \times 10^{11} \mathrm{~m}^{3}$ in April to May, and the $50 \mathrm{mSv}$ for August corresponds to $v_{\mathrm{lc}} \approx 3.5 \times 10^{11} \mathrm{~m}^{3}$.

If this was to generate the two observed Labrador Sea freshwater events of $\Delta v_{\mathrm{ls}}=0.8 \times 10^{11} \mathrm{~m}^{3}$ and $2 \times$ $10^{11} \mathrm{~m}^{3}$, the required $\chi$ would be approximately 0.1 and 0.5 , respectively. Thus, only a small fraction of Labrador Current water would need to be carried into the interior LS to cause the observed first freshening in May, while much of the second LC freshwater pulse needs to reach the central LS to explain the summer pulse there.

In the vicinity of the central Labrador Sea there is no evidence of reoccurring instabilities in the Labrador Current that might exchange properties with the central Labrador Sea. There is no data showing LC water being detrained or mixed into the upper LS (only the reverse process has been observed). Thus. it is unreasonable to assume that the second, larger, freshwater peak in the Labrador Sea originates from the LC. However, a small mixing of 0.1 of the LC volume may be hard to detect observationally and can thus not be excluded. Therefore, since the timing matches and only a small water input from the LC is necessary, the first freshening in the central Labrador Sea may originate in the Labrador Current.

\section{Discussion}

We have found two separate freshwater pulses in the freshening phase of the seasonal salinity cycle in the central Labrador Sea. None of them can be explained solely through local sources.

The second pulse accounts for $60 \%$ of the freshwater found in the Labrador Sea in late summer. According to our analyses, the West Greenland Current is the only possible source of this second pulse. Surface drifters indicate water exchange or input between the WGC and the central LS. The timing of the freshwater pulses in both regions matches very well, and the freshwater volume calculations are in good agreement. This is not contradictory to tracer analyses (e.g., Khatiwala et al. 2002), which exclude the WGC as a source. These analyses and research cruises took place mainly in June. Prior to August only the first pulse of the freshening is present and therefore does not include the second part of the freshening (cf. Fig. 5).

The first freshwater pulse found in the central LS represents about $20 \%$ of the freshwater present at the end of summer. Tracing this pulse to its source is less clear than for the second one. Since the timing matches and only one-tenth of LC water needs to be diverted to the LS to generate this, the LC is a possible source for the early freshening. Other support for this scenario comes from tracer analyses by Khatiwala et al. (2002) who find an influence of Baffin Bay waters and restratification of the convection area, which might cause the LC to flow farther offshore or entrain parts of the LC. But, while in the WGC no freshwater pulse was observed, which could explain the early freshening in the LS, recent altimetry analysis (e.g., Lilly et al. 2003) shows a seasonal EKE maximum in the WGC region propagating into the central LS, with maximum EKE in the central LS in May. The corresponding eddies have a fresh top, which therefore could be a possible source for this first freshwater pulse. Thus both the LC as well as the WGC cannot be completely ruled out as a source of the first freshening in the Labrador Sea.

With these origins of Labrador Sea freshwater$60 \%-80 \%$ from the WGC and $20 \%$ from precipitation-a causal connection between central LS convective activity and the main WGC freshwater sources, like sea ice melt and Fram Strait freshwater export, must dominate over salinity anomalies originating from or passing through the Baffin Bay area. These results help to quantify and understand the pathways of the known influence of Arctic freshwater export on the LS convection, such as the Great Salinity Anomaly (see introduction). The above ratios also support the model results by Myers (2005). Even though the Myers results confirm the minor importance of Baffin Bay waters for the central Labrador Sea like our observational study does, our results, that is, the two separate freshwater signals and their origin, have not been reproduced with model simulations yet.

Acknowledgments. This work was funded by the Deutsche Forschungsgemeinschaft, Bonn (SFB 460). Two anonymous reviewers provided very useful suggestions to improve the text. 


\section{REFERENCES}

Aagaard, K., and E. C. Carmack, 1989: The role of sea ice and other fresh water in the Arctic circulation. J. Geophys. Res., 94, 14 485-14 498.

Buch, E., 2000: Air-sea-ice conditions off southwest Greenland, 1981-97. J. Northw. Atl. Fish. Sci., 26, 123-136.

Cuny, J., P. B. Rhines, P. P. Niiler, and S. Bacon, 2002: Labrador Sea boundary currents and the fate of the Irminger Sea Water. J. Phys. Oceanogr., 32, 627-647.

Dickson, R. R., J. Meincke, S.-A. Malmberg, and A.-J. Lee, 1988: The Great Salinity Anomaly in the northern North Atlantic 1968-1982. Progress in Oceanography, Vol. 20, Pergamon Press, 103-151.

_ _ J. Lazier, J. Meincke, and P. Rhines, 1996: Long-term coordinated changes in the convective activity of the North Atlantic. Decadal Climate Variability: Dynamics and Predictability, D. L. T. Anderson and J. Willebrand, Eds., NATO ASI Series I: Global Environmental Change, Vol. 144, Springer-Verlag, 211-261.

Drinkwater, K. F., 1988: On the mean and tidal currents in Hudson Strait. Atmos.-Ocean, 26, 252-266.

Eden, C., and C. Böning, 2002: Sources of eddy kinetic energy in the Labrador Sea. J. Phys. Oceanogr., 32, 3346-3363.

Haak, H., J. Jungclaus, U. Mikolajewicz, and M. Latif, 2003: Formation and propagation of Great Salinity Anomalies. Geophys. Res. Lett., 30, 1473, doi:10.1029/2003GL017065.

Houghton, R. W., and M. H. Visbeck, 2002: Quasi-decadal salinity fluctuations in the Labrador Sea. J. Phys. Oceanogr., 32, 687701.

Katsman, C. A., M. A. Spall, and R. S. Pickart, 2004: Boundary current eddies and their role in restratification of the Labrador Sea. J. Phys. Oceanogr., 34, 1967-1983.

Khatiwala, S. P., R. G. Fairbanks, and R. W. Houghton, 1999: Freshwater sources to the coastal ocean off northeastern North America: Evidence from $\mathrm{H}_{2}{ }^{18} \mathrm{O} / \mathrm{H}_{2}{ }^{16} \mathrm{O}$. J. Geophys. Res., 104, 18 241-18 255.

_ - P. Schlosser, and M. Visbeck, 2002: Rates and mechanisms of water mass transformation in the Labrador Sea as inferred from tracer observations. J. Phys. Oceanogr., 32, 666-686.

Kwok, R., G. F. Cunningham, and S. S. Pang, 2004: Fram Strait sea ice outflow. J. Geophys. Res., 109, C01009, doi:10.1029/ 2003JC001785.

Lab Sea Group, 1998: The Labrador Sea deep convection experiment. Bull. Amer. Meteor. Soc., 79, 2033-2058.

Lazier, J. R. N., 1980: Oceanographic conditions at Ocean Weather Ship Bravo 1964-1974. Atmos.-Ocean, 18, 227-238. 1995: The salinity decrease in the Labrador Sea over the past thirty years. Natural Climate Variability on Decade-toCentury Time Scales, D. G. Martinson et al., Eds., National Academy Press, 295-304.

, and D. G. Wright, 1993: Annual velocity variations in the Labrador Current. J. Phys. Oceanogr., 23, 659-678.

Lilly, J. M., P. B. Rhines, F. Schott, K. Lavender, J. Lazier, U. Send, and E. D'Asarp, 2003: Observations of the Labrador Sea eddy field. Progress in Oceanography, Vol. 59, Pergamon Press, 75-176.
Loder, J. W., B. Petrie, and G. Garwarkiewicz, 1998: The coastal ocean off northeastern North America: A large scale view. The Sea: The Global Coastal Ocean, A. R. Robinson and K. H. Brink, Eds., Regional Studies and Syntheses, Vol. 11, John Wiley and Sons, 105-133.

Marshall, J., and F. Schott, 1999: Open-ocean convection: Observations, theory, and models. Rev. Geophys., 37, 1-64.

- H. Johnson, and J. Goodman, 2001: A study of the interaction of the North Atlantic Oscillation with ocean circulation. J. Climate, 14, 1399-1421.

Mertz, G., S. Narayanan, and J. Helbig, 1993: The freshwater transport of the Labrador Current. Atmos.-Ocean, 31, 281295.

Mineral Resource Administration for Greenland, 1998: Physical environment of eastern Davis Strait and northeastern Labrador Sea, an overview. Danish Meteorological Institute Tech. Rep., Copenhagen, Denmark, 44 pp.

Myers, P. G., 2005: Impact of freshwater from the Canadian Arctic Archipelago on Labrador Sea Water formation. Geophys. Res. Lett., 32, L06605, doi:10.1029/2004GL022082.

Myers, R. A., S. A. Akenhead, and K. Drinkwater, 1990: The influence of Hudson Bay runoff and ice-melt on the salinity of the inner Newfoundland shelf. Atmos.-Ocean, 28, 241-256.

Mysak, L. A., D. K. Manak, and R. F. Marsden, 1990: Sea-ice anomalies in the Greenland and Labrador Seas during 19011984 and their relation to interdecadal Arctic climate cycle. Climate Dyn., 5, 111-133.

Paterson, W. S. B., 1994: The Physics of Glaciers. 3d ed. Elsevier, $480 \mathrm{pp}$.

Peterson, I. K., S. J. Prinsenberg, and P. Langille, 2000: Sea ice fluctuations in the western Labrador Sea (1963-1998). Canadian Tech. Rep. of Hydrography and Ocean Sciences, Tech. Rep. 208, v+51 pp.

Pickart, R. S., D. J. Torres, and R. A. Clarke, 2002: Hydrography of the Labrador Sea during active convection. J. Phys. Oceanogr., 32, 428-457.

Reeh, N., 1985: Greenland ice-mass balance and sea-level change. Glaciers, ice sheets and sea level: Effects of a $\mathrm{CO}_{2}$-induced climatic change. U. S. Dept. of Energy Rep. DOE/ER/60235$1,155-171$.

Sathiyamoorthy, S., and G. W. K. Moore, 2002: Buoyancy flux at Ocean Weather Station Bravo. J. Phys. Oceanogr., 32, 458474.

Schmidt, S., 2003: Frischwassereinflüße auf die Konvektionsaktivität in der Labradorsee (Freshwater influence on convection activity in the central Labrador Sea). Diploma Thesis, Physical Oceanography Dept., Institut für Meereskunde, Kiel, Germany, 82 pp.

Wadhams, P., 2000: Ice in the Ocean. Gordon and Breach, 351 pp.

Walsh, J. E., and D. H. Portis, 1999: Variations of precipitation and evaporation over the North Atlantic Ocean, 1958-1997. J. Geophys. Res., 104, 16 613-16 631.

Wang, J., L. A. Mysak, and R. G. Ingram, 1994: Interannual variability of sea-ice cover in Hudson Bay, Baffin Bay and the Labrador Sea. Atmos.-Ocean, 32, 421-447. 